\section{Radiation Induced Loss of Anti-Ig Binding Ability of Lymphocytes}

\section{F. Ojeda and M. Flores}

Radiation Laboratory, Physics Department, Universidad Austral de Chile, Valdivia-Chile

and

\section{H. Folch}

Experimental Medicine Department, Universidad Austral de Chile, Valdivia-Chile, Casilla 567

Z. Naturforsch. 34 c, $888-889$ (1979);

received January 30,1979

Lymphocytes, Receptors, Irradiation

The effect of irradiation on the anti Ig binding ability of lymphocytes after irradiation was studied. Normal control and irradiated lymphoid cells were treated with rabbit anti mouse IgG fluorescein conjugated serum and the fluorescein positive cells compared. A reduction in the proportion of stained cells in the irradiated lymphocytes was found. It depends on the dose and on the incubation time at $37^{\circ} \mathrm{C}$ after irradiation. The maximum effect was detected after 10 minutes of incubation, longer incubation is associated with a partial recovery of the stainability of the IgG receptors.

The high sensitivity of artificial phospholipid membrane toward radiation induced peroxidation $[1,2]$ raises new questions of possible effects of irradiation on natural membranes. Although subcellular particles have been reported to be relatively radioresistant $[3,4]$, parameters related to the plasma membrane, such as the lectin-binding ability and the electrophoretic motility, have been reported to be radiosensitive to $90-100$ rads. $[5,6]$. In this context, and because of the close relatioship between structural parameters of the lymphocyte plasma membrane and its functions, we investigated the effect of irradiation on the accessibility of immunoglobulins on the lymphocyte surface.

Lymphocytes were taken from peripheral lymph nodes of $6-7$ weeks old RK mice by gently teasing the organs and passing the cell suspension through gauze in Hanks supplemented with $0.023 \%$ Hepes buffer (SIGMA, Chemical Company, St. Louis, USA) at $\mathrm{pH}$ 7.4. After washing the cells were adjusted at $5 \times 10^{7} \mathrm{cell} / \mathrm{ml}$ and irradiated with X-Rays $(120 \mathrm{KV}, 4 \mathrm{~mA}$, total filtration $3.5 \mathrm{~mm} \mathrm{Al}+2 \mathrm{~mm}$

Reprint requests to Dr. F. Ojeda. 0341-0382/79/0900-0888 \$01.00/0

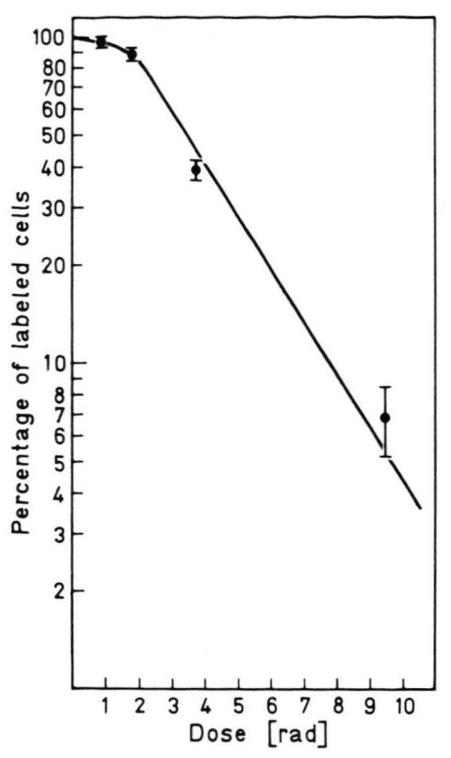

Fig. 1. Dose dependence of the percentage of FITC-anti IgG labelled cells with respect to the nonirradiated control after 10 minutes incubation at $37^{\circ} \mathrm{C}$. Each point represents the mean of 3 to 9 independent experiments. Bars represent the standard deviation.

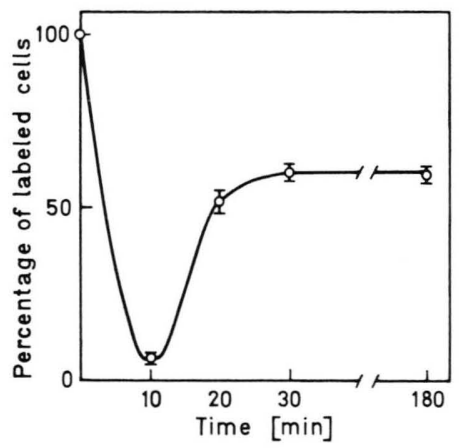

Fig. 2. Percentage of FITC-anti IgG labelled cells depending on the incubation time after irradiation with $9.5 \mathrm{rad}$. Each point represents the mean of 3 to 9 independent experiments. Bars represent the standard deviation.

Pyrex Glass, SSD $60 \mathrm{~cm}$ ) at a dose rate of $7.12 \mathrm{rad} /$ min. After irradiation the cell suspensions were incubated from $10 \mathrm{~min}$ to $3 \mathrm{~h}$ at $37^{\circ} \mathrm{C}$. The subsequent staining with fluorescein labelled anti $\operatorname{IgG}$, (FITC-anti IgG, Hyland, Div. Travemol Lab., Inc., Los Angeles, California, USA) was performed by incubating $10^{7}$ cells in $0.1 \mathrm{ml}$ of FITC-anti IgG $(50 \mu \mathrm{g}$ / $\mathrm{ml}$ ) at $37^{\circ} \mathrm{C}$ for 15 minutes. Unbound Anti IgG was washed out 3 times.

To detect the number of fluorescent cells, 200 to 300 cells were screened with a Zeiss Fluorescence 
microscope for each dose and time point. The percentage of labelled cells in nonirradiated controls was $20 \% \pm 0.5 \%$ in agreement with othe authors [7]. The values in the Figures are expressed as fraction of the control for each experiment and experimental condition.

As it can be seen from Fig. 1, the presence of cells stained with fluorescin labelled anti IgG diminished after irradiation. The slope of the linear portion of the curve gives a sensitivity corresponding to $\mathrm{D}_{37}=3.0$ rads. From Fig. 2 , it can be seen that the magnitude of the radiation effect is dependent on the incubation time at $37^{\circ} \mathrm{C}$. After a fast disappearance the number of cells able to be stained with FITC-anti IgG diminished rapidly within the first 10 minutes, but the ability to be stained recovered during the next 20 minutes. Further incubation up to $3 \mathrm{~h}$ gives no additional recovery for cells irradiated with $9.5 \mathrm{rad}$.

Control experiments were done in which irradiated and control cells were passed after irradiation through a discontinuous BSA gradient $(6.67 \%$ BSA, 3.3\% BSA and $1.67 \%$ BSA prepared in Hanks Medium). Afterwards the cells were washed twice In Hanks' solution. The following procedure was

[1] A. Pektau and W. S. Chelack, Biochim. Biophys. Acta 433, $445-456$ (1976).

[2] J. A. Raleigh and W. Kremers, Int. J. Radiat. Biol. 34, $439-447$ (1978).

[3] E. D. Wills, Int. J. Radiat. Biol. 11, 5 - 17 (1966).

[4] F. Ojeda, A. Schraub, and E. L. Sattler, Strahlentherapie 153, $117-123$ (1977). the same as stated above. Cells were incubated for 10 minutes. The described treatment had no effect on irradiated nor on control cells. From this experiment it can be stated that no radiation induced soluble products interfere with the measurement.

The present experiments indicate that irradiation causes a transcient decrease in the accessibility of surface immunoglobulins, without changes observed in cap formation. The measured effect is probably a consequence of a sensitive membrane change which may have other biological expression. Although the nature of the membrane change is not known the temporary changes in the binding behaviour of the antigen receptors may have consequences on lymphocytes immunological events after irradiation with low doses at low dose rates.

\section{Acknowledgements}

We acknowledge Mr. E. Carrasco M. from Univ. Técnica del Estado for the irradiation facility.

This work was supported by International Atomic Energy Agency contract 2175/RB, PNUD grant 102/77, U. A. CH. grant C. $77 / 8$.

[5] C. Sato, K. Kojima, K. Nishizawa, Rad. Res. 69, $367-374$ (1977)

[6] G. J. Koteles, T. Kubasowa, and L. Varga, Nature 259, $507-508$ (1976).

[7] M. Mac. Willimans, M. E. Lamm, and J. M. PhillipsQuagliata, J. Immunol. 113, 1326 (1974). 